\title{
Relações Intersetoriais entre a Indústria de Transformação e Diferentes Segmentos de Serviços: Um exame por meio de Análise de Rede em matrizes de insumo-produto (1995 e 2010)
}

\author{
Vinicius Cardoso de Barros Fornari* \\ Rogério Gomes** \\ Celio Hiratuka***
}

Área ABEIN: 1.1 Dinâmicas industriais setoriais e dos sistemas de produção

RESUMO: Este estudo examina as mudanças ocorridas nas últimas décadas nos vínculos entre as diferentes atividades da economia, especialmente nos elos entre as atividades de serviços e industriais. Para esse exame são analisados os vínculos (direções) e as intensidades (valor) das relações intersetoriais das maiores economias mundiais em 1995 e 2010. A pesquisa está estruturada em dois pontos básicos: 1) revisão das abordagens teóricas sobre a evolução e os vínculos entre as atividades industriais e de serviços na economia, e; 2) indicadores estimados a partir da combinação da metodologia de Análise de Redes (software Pajek) sobre os dados das matrizes de insumo-produto nacionais (WIOD, 2014). Os resultados apontam para uma forte complementariedade entre a indústria de transformação e alguns segmentos de serviços.

\begin{abstract}
This study examines the changes that have occurred in the last decades in the links between the different activities of the economy, especially in the links between service and manufacturing activities. This analysis examines the links (directions) and intensities (value) of the intersectoral relations of the world's largest economies in 1995 and 2010. The research is structured in two basic points: 1) review of theoretical approaches on evolution and the links between manufacturing and service activities in the economy, and; 2) indicators estimated from the combination of the Network Analysis (Pajek software) on data from the national input-output matrices (WIOD, 2014). The results point to a strong complementarity between the manufacturing and some services segments.
\end{abstract}

Palavras-chave: relações intersetoriais; atividades industriais e de serviços; análise de rede; matriz insumo-produto.

Códigos JEL: O14; O20; O25

* Universidade Estadual de Campinas (Unicamp), Campinas (SP), Brasil. E-mail: viniciuscbfornari@gmail.com.

** Faculdade de Ciências e Letras/Universidade Estadual Paulista (FCLAr/Unesp), Araraquara (SP), Brasil. E-mail: rgomes@fclar. unesp.br.

*** Universidade Estadual de Campinas (Unicamp), Campinas (SP), Brasil. E-mail: celiohiratuka@gmail.com. 


\section{Introdução}

O aumento da participação das atividades de serviços na economia é debatido na literatura desde a década de 1930 (FISHER, 1935; CLARK, 1940; KUZNETS,1957; BAUMOL, 1967). Desse período datam também os primeiros estudos sobre desenvolvimento que procuraram hierarquizar as atividades econômicas, mostrando, em particular, a importância do setor secundário para a estruturação do terciário (PREBISCH, 1949; HIRSCHMAN, 1958; KALDOR, 1967; THIRLWALL, 2005). Alguns aspectos dessa problemática estão presentes em estudos que entendem desindustrialização como um processo inerente ao desenvolvimento econômico, ou seja, como um fenômeno natural e benéfico das economias que seguem as "etapas dos três setores" (SINGH, 1987; ROWTHORN e RAMASWANY, 1999; PALMA, 2005; TREGENNA, 2008).

A abordagem dos três setores consiste em avaliar a participação das atividades primária (agrícola e extração mineral), secundária (bens de consumo e investimentos ligados aos setores industrial e de construção) e terciária (serviços) por meio, em geral, do nível de empregos e/ou do valor adicionado a longo do processo de desenvolvimento econômico. É suposto que nesse processo há uma progressão gradual, frequentemente coligado ao nível da renda per capita: (1) no estágio inicial, o predomínio é do setor primário tanto em termos de emprego e de criação de riqueza; (2) a expansão desta atividade transborda e incita o setor secundário, que progressivamente ganha importância e passa a "sustentar" o crescimento dos demais setores, seja pela demanda de insumos, seja pela transferência de progresso técnico incorporada nos produtos fornecidos; (3) o crescimento das atividades industriais fomenta o setor terciário que terminam por concentrar a maior parte do emprego e do valor adicionado. Esse padrão, que associa atividade "dominante" e estágio de desenvolvimento, foi observado primeiramente por Fisher (1935) e Clark (1940), e, posteriormente, analisados nos trabalhos de Kuznets (1957 e 1966) e Kongsamut et al. (2001). No entanto, não há consenso sobre a "naturalidade" dessa abordagem, especialmente quando se trata de economias em desenvolvimento (FEIJÓ e CARVALHO, 2007; NASSIF, 2008; BRESSER-PEREIRA e MARCONI, 2010; CANO, 2012).

Nas últimas décadas, o setor de serviços tem ampliado o seu papel nas cadeias internacionais de valor e a sua importância nas economias nacionais. Entretanto, parcela das mudanças recentes nas estruturas das economias nacionais não parece atrelada unicamente as etapas do desenvolvimento econômico (OCDE, 2013). No que tange ao crescimento dos setores industriais vis à vis serviços, ao contrário de uma visão de "conflito" ou "rivalidade", este estudo pressupõe que as interações entre as duas atividades estão adquirindo características mais consistentes e complexas, que se reforçam por laços de complementaridade.

Este estudo visa contribuir para o detalhamento das mudanças na participação das atividades de serviços na economia, compará-las entre si e, em especial, quantificar a intensidade das relações de cada um dos seus segmentos com a indústria. Esse objetivo é buscado por meio do exame das modificações nos coeficientes de insumo-produto nacionais das doze maiores economias do mundo (Alemanha, Brasil, China, Coreia, EUA, França, Índia, Itália, Japão, México, Reino Unido e Rússia) nos anos de 1995 e 2010. Essas economias são examinadas individualmente, mas, principalmente, ressaltando as diferenças entre dois blocos de países - desenvolvidos (PD) e em desenvolvimento (PED).

Considerando que a finalidade do estudo é examinar as relações entre as atividades de serviços e industriais, a pesquisa agrega a economia em três setores (Recursos 
Naturais; Indústria de Transformação; Construção) e divide os Serviços em quatro segmentos: Distribuição; Sociais, Pessoais; Produtivos. Essa classificação para o terciário é compatibilizada na World Input-Output Database (WIOD, 2014), fontes das estatísticas utilizadas (matrizes das contas nacionais).

$\mathrm{Na}$ análise são empregados dois indicadores utilizados de forma complementar. $\mathrm{O}$ primeiro, a participação do valor adicionado (contribuição ao PIB) permite avaliar a dimensão de cada um dos agregados e/ou segmentos na economia. O segundo, uma adaptação do Índice de Ligação de Rasmussen-Hirschman (RASMUSSEN, 1956; HIRSCHMAN, 1958), é um índice que busca indicar os setores com maior poder de encadeamento, alavancagem ou impacto na economia (i) para trás (demanda sobre as demais atividades) e (ii) para frente (oferta).

Além desta introdução, o estudo está estruturado em três itens. O item dois visita a literatura para ressaltar as principais abordagens e características das atividades de serviços. Após a descrição da metodologia utilizada, o item três apresenta e examina os resultados encontrados. O quarto e último item tece algumas considerações adicionais sobre os resultados do estudo.

\section{Características das Atividades de Serviços}

Na literatura há quatro abordagens principais que procuram explicar o crescimento da importância dos setores de serviços na economia: i) mudanças na estrutura da demanda final que decorrem do aumento da renda e reforçam o consumo de serviços; ii) intensificação do uso do fator capital no secundário - e consequente aumento relativo da produtividade industrial - desloca trabalho para o setor terciário; iii) a crescente especialização do setor de serviços, que favorece a terceirização, e; iv) incorporação de atividades industriais pelos de serviços. Nos últimos anos, a literatura específica tem dedicado atenção a terceira e quarta abordagens. Em comum, essas pesquisas apontam para heterogeneidade dessa atividade e descrevem as suas características, principalmente, a partir do potencial de agregação de valor e mecanismos de inovação (MIOZZO e SOETE, 2001; SCHETTKAT e YOCARINI, 2006; HOWELLS, 2006; GALLOUJ e SAVONA, 2008; 'CASTELACCI, 2008).

A heterogeneidade é uma das características mais importantes das atividades de serviços. Em função dessa particularidade, Singelmann (1978) classifica os tipos de serviços em quatro grupos (os respectivos segmentos estão detalhados no Quadro 1): i) serviços de distribuição; ii) serviços produtivos; iii) serviços sociais; iv) serviços pessoais. Nesse arranjo, as duas primeiras categorias são consideradas "intermediárias", ou seja, aquelas utilizadas como insumo para produção, e as duas últimas como "finais", uma vez que são direcionadas ao consumo final.

Para Park e Chan (1989; 201-2), as categorias acima distinguem principalmente os fatores que regulam a oferta e demanda. Por exemplo, à medida que avança o processo de industrialização é adensada a relação simbiótica direta entre setor industrial e serviços de produtivos e de distribuição. Por outro lado, a produção e o emprego associados aos serviços pessoais não dependem abertamente da indústria, mas são afetados pelos efeitos indiretos induzidos pela renda gerada nessa atividade. Para o autor, esses serviços passam por mudanças fundamentais no decorrer do processo de industrialização. Nas fases iniciais desse processo, a maioria desses serviços é fornecida de versões simples e sem (ou pouca) diferenciação. Com o desenvolvimento da economia, induzida pelo aumento da renda per capita e em resposta às exigências dos consumidores, a gama de serviços 
pessoais ofertada no mercado se expande, cresce a especialização e a sofisticação dos produtos oferecidos. De forma análoga, por serem considerados bens superiores com elasticidades-renda elevadas, a industrialização fomenta a prestação dos serviços sociais.

Para Howells (2006; 9), duas tendências paralelas associadas às mudanças na divisão internacional do trabalho ajudam a explicar o aumento da agregação de valor nesse setor: outsourcing (subcontratação e terceirização) $e$ offshoring (organização da manufatura em diferentes países). Na década de 1980, almejando a redução de custos, as funções empresariais de baixa qualificação da mão de obra - serviços de alimentação, limpeza, segurança, etc - foram o foco inicial da terceirização (outsourcing). Posteriormente, as atividades intensivas em conhecimento e de maior valor agregado, como tecnologia da informação (TI), $\mathrm{P} \& \mathrm{D}$ e serviços jurídicos, também foram externalizadas.

Associado ao processo da terceirização, o offshoring (internacionalização de algumas atividades corporativas com ou sem outsourcing) tem favorecido o aumento das atividades de serviços de duas formas: i) as empresas que utilizam prestadoras de serviços nos mercados onde se estabelecem; ii) as empresas contratam serviços de empresas sediadas no exterior, isto é, por meio de subcontratação ou terceirização internacional (HOWELLS, 2006; 9). Para Schettkat e Yocarini (2005; 145), além da terceirização e offshoring, a especialização e o direcionamento para demanda final possibilitaram o crescimento e as inovações no setor, ou seja, o desenvolvimento e aumento da participação dos serviços na economia.

Para Arbache $(2014 ; 20)$, as atividades de serviços e indústria se relacionam por meio de duas famílias distintas e complementares de vínculos. A primeira, ligada aos custos de produção, diz respeito aos elos entre indústria e os serviços de logística e transportes, infraestrutura em geral, armazenagem, reparos e manutenção, serviços produtivos terceirizados e infraestrutura em geral, comunicações, serviços financeiros, viagens, acomodação, alimentação, distribuição, dentre outros. A segunda família, associada com agregação valor, diferenciação e customização de produtos, congrega as vinculações entre o setor industrial e os serviços de $\mathrm{P} \& \mathrm{D}$, design, projetos de engenharia e arquitetura, consultorias, softwares, serviços técnicos especializados, serviços sofisticados de tecnologias da informação, branding, marketing, comercialização, etc.

Essa última família de elos é permeada por relações mais sofisticadas que requerem maior grau de conhecimento técnico e incorporam trabalho qualificado. Nas últimas décadas, o espessamento dessas capacitações, potencializado pelas inovações em processo, diferenciação de produtos e criação de novos modelos de negócios, permitiu que esses segmentos aumentassem a sua parcela no valor gerado pelas atividades de serviços. Além disso, em termos de composição do valor adicionado ao longo da cadeia de valor, a parcela da manufatura (etapa intermediária) vem sendo gradativamente reduzida em benefício das etapas pré-produção ( $\& \& D$, Projetos e Logística com alto, médio baixo valor adicionado, respectivamente) e pós-produção (Vendas, Marketing e Logística, idem) (OCDE, 2013; 217). Nessa perspectiva, o processo de desenvolvimento econômico não é apenas uma questão de partilha ou (re)distribuição da renda (ou emprego) entre as atividades econômicas, ou de fortalecimento de certos serviços em detrimento da manufatura, mas um processo de transferência, construção e/ou reforço das atividades de serviços intensivas em conhecimentos vinculadas a indústria em âmbito global.

A reestruturação das atividades produtivas nas diferentes economias está associada à velocidade e ao grau de inovação tecnológica nos processos produtivos e 
organizacionais ligados ao setor de serviços, mais especificamente aos campos da telemática, serviços de informática e processos de telecomunicações, relacionados à transferência de informação e conhecimento (KON, 2007; 27). Kon (2013; 84) destaca que o papel dos serviços é mais do que complementar das atividades manufatureiras, pois é fundamental para intensificar a sua capacidade de inovação, produção, circulação, distribuição e regulação. Note-se, no entanto, que sem as primeiras atividades, inexistem as últimas. Nesse sentido, prevalece percepção de complementariedade entre as duas atividades econômicas sobre a visão "clássica" de rivalidade.

Para Greenhalgh e Gregory (2001; 644), há efeitos de retroalimentação entre as mudanças (expansão do setor e da adição de valor) e as inovações ocorridas nas atividades de serviços. Gallouj e Savona $(2008 ; 155)$ classifica as inovações em serviços em três tipos: i) tecnológica - emprego ou absorção de tecnologias de outras indústrias, por exemplo, das tecnologias de informação e comunicação (TIC); ii) orientada para diferenciação dos serviços - a intensificação da customização dos serviços e; iii) integrada - que avalia a tendência para a convergência entre produtos manufaturados e prestação de serviços. Os dois últimos tipos de inovações estão relacionados aos chamados novos modelos de negócios, onde os bens manufaturados são vendidos ou alugados com grande customização a partir da diferenciação de serviços.

Em particular, o significado do primeiro tipo acima, inovação tecnológica, está centrado no uso cada vez mais intensivo de tecnologias industriais nos setores de serviços. Como a absorção dessas tecnologias é muitas vezes materializada pela adoção de equipamentos, a distinção entre a origem dos produtos, se industriais ou dos serviços, pode ser motivo de polêmica. Nesses casos, ainda que a atividade geradora de renda seja a atribuída aos serviços, o papel da indústria é fundamental na oferta de tecnologias para o terciário (GALLOUJ e SAVONA, 2008).

Tomando com base o estudo de Pavitt (1984), Miozzo e Soete (2001) desenvolvem uma taxonomia para analisar as capacidades de inovação e as interações nas atividades de serviços. Os autores classificam as atividades de serviços em três grupos. $\mathrm{O}$ primeiro é o Dominado pelo Fornecedor: Serviços pessoais (restaurantes, hotéis, lavandaria, serviços de reparação, cabelereiros e outros serviços de beleza) e serviços públicos e sociais. As empresas do primeiro segmento são geralmente pequenas, com pouco ou nenhum desenvolvimento de $\mathrm{P} \& \mathrm{D}$ e engenharia. As contribuições tecnológicas dessas firmas são poucas, restritas a competências profissionais, marcas comerciais e publicidade. As firmas do segundo segmento, serviços públicos e sociais, são grandes organizações. Em ambos os casos, as empresas fazem apenas contribuições menores para o processo tecnológico e a maioria das inovações vêm de fornecedores de insumos e equipamentos.

O segundo tipo de serviços é o das Redes Físicas Intensivas em Escala e Redes de Informação. $\mathrm{O}$ primeiro segmento, redes físicas intensivas em escala, envolve processos em grande escala, considerável divisão de trabalho, simplificação de tarefas e substituição de trabalhado por máquinas - empresas de serviços de transportes e comércio, distribuição de eletricidade e gás, etc. O desenvolvimento está intimamente relacionado com a aplicação de tecnologia de comunicação, comumente voltada para a redução dos custos. O segundo segmento inclui firmas dependentes de redes de informação (comunicações). Em ambos os segmentos as inovações tecnológicas têm origem na indústria, com a adoção de máquinas e equipamentos, mas a natureza dessas inovações é fortemente determinada pelo seu uso nas firmas de serviços. 
O terceiro grupo de serviços da taxonomia é denominado Baseado Ciência e Fornecedores Especializados. Nas últimas décadas surgiu um número crescente de serviços relacionados à $\mathrm{P} \& \mathrm{D}$, software, etc., e ao desenvolvimento e aplicação das tecnologias da informação. Em todas estas atividades, as principais fontes de tecnologia são P\&D e atividades de programação (softwares) pelas próprias firmas. Como essas atividades são intensivas em mão de obra qualificada, em geral os "bens produzidos" incorporam alto grau de conhecimento técnico-científico.

Castellacci (2008) também desenvolveu uma tipologia a partir de uma análise empírica com dados Community Innovation Survey (CIS) da União Europeia, ${ }^{1}$ complementar a proposta anterior. $\mathrm{O}$ autor desagrega o setor de serviços em três grupos: i) Intensivos em conhecimento - compreende os fornecedores de conhecimento especializado e soluções técnicas como software, $P \& D$, engenharia e consultoria, ou seja, os serviços com grande capacidade tecnológica e de geração de conhecimento; ii) Serviços de infraestrutura física (transporte, comércio, etc.) e de rede (finanças, telecomunicações, atividades que manuseiam informações, etc.): composto por empresas que prestam serviços especializados e intermediários na cadeia produtiva, mas que as inovações estão concentrada na capacidade de absorção para o aumento da eficiência, comumente via aquisição de maquinas e equipamentos; iii) Serviços pessoais dominados pelos fornecedores (hotéis, restaurantes, etc.): as inovações estão relacionadas à organização dos serviços oferecidos (CASTELLACCI, 2008; 992).

O Quadro 1 representa o esforço de classificar os agregados de serviços adotados na World Input-Output Database (WIOD, 2014) - fonte dos dados para a análise das próximas seções deste estudo - de acordo com as tipologias apresentadas acima. Além da heterogeneidade ressaltada acima, esse quadro procura retratar algumas características tecnológicas dos serviços. As principais características dessa atividade estão atreladas ao direcionamento da demanda (especialização), capacidade de inovação de cada segmento e potencial de geração de valor adicionado. A próxima seção analisa relações intersetoriais das atividades de serviços nos países selecionados com base nesses estudos.

\footnotetext{
${ }^{1}$ Originalmente desenvolvida para os setores industriais e de serviços, aqui destacamos apenas os aspectos relacionados aos serviços dessa taxonomia.
} 


\begin{tabular}{|c|c|c|c|c|c|c|c|}
\hline Setores Matriz WIOD (2014) & \multicolumn{2}{|c|}{$\begin{array}{l}\text { Grupo de Serviços - } \\
\text { Singelmann (1978) }\end{array}$} & \begin{tabular}{|c|} 
Relação entre \\
Indústria e Serviços - \\
Arbache (2014)
\end{tabular} & $\begin{array}{c}\text { Geração de Valor } \\
\text { Adicionado (OCDE, } \\
\text { 2013) }\end{array}$ & $\begin{array}{c}\text { Abordagem da } \\
\text { Inovação } \\
\text { Gallouje Savona (2008) }\end{array}$ & \begin{tabular}{|} 
Taxonomia - \\
Miozo e Soete \\
(2001)
\end{tabular} & $\begin{array}{c}\text { Taxonomia - } \\
\text { Castellacci (2008) }\end{array}$ \\
\hline Comércio por atacado & \multirow{10}{*}{ 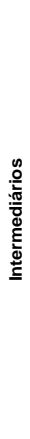 } & \multirow{6}{*}{$\begin{array}{l}\text { Serviços de } \\
\text { Distribução }\end{array}$} & \multirow{9}{*}{ Custos de produção } & \multirow{2}{*}{ Vendas - Alto VA } & \multirow{9}{*}{$\begin{array}{l}\text { Orientada para } \\
\text { diferenciação dos } \\
\text { serviços }\end{array}$} & \multirow{6}{*}{$\begin{array}{l}\text { Redes físicas } \\
\text { intensiva em } \\
\text { escala }\end{array}$} & \multirow{8}{*}{ Infraestrutura física } \\
\hline Comércio por varejo & & & & & & & \\
\hline Transportes Terrestres & & & & \multirow{4}{*}{ Logística - Baixo VA } & & & \\
\hline Transporte Aquaviário & & & & & & & \\
\hline Transporte Aéreo & & & & & & & \\
\hline $\begin{array}{l}\text { Agências de viagem e Outros Apoios Auxiliares de } \\
\text { Atividades de Transporte }\end{array}$ & & & & & & & \\
\hline Electricidade, Gás e Abastecimento de Água & & \multirow{4}{*}{$\begin{array}{l}\text { Serviços } \\
\text { Produtivos }\end{array}$} & & & & \multirow{2}{*}{$\begin{array}{l}\text { Dominado por } \\
\text { fornecedor }\end{array}$} & \\
\hline Atividades Imobiliárias & & & & & & & \\
\hline Intermediação Financeira & & & & & & $\begin{array}{l}\text { Redes de } \\
\text { Informaccão }\end{array}$ & Infraestrutura de rede \\
\hline $\begin{array}{l}\text { Locação de Máquinas e Equipamentos; Outras } \\
\text { Atividades de Negócios }\end{array}$ & & & $\begin{array}{c}\text { Custos de produção e } \\
\text { Agregaçãa de valor }\end{array}$ & $\begin{array}{l}\text { P\&D e Projetos- Alto } \\
\text { VA }\end{array}$ & $\begin{array}{l}\text { Integrada e } \\
\text { Tecnológica }\end{array}$ & \begin{tabular}{|c|} 
Baseado \\
Ciência e \\
Fornecedores \\
Especializados
\end{tabular} & $\begin{array}{l}\text { Intensivos em } \\
\text { conhecimento }\end{array}$ \\
\hline Correios e Telecomunicações & \multirow{7}{*}{$\stackrel{\frac{n}{\pi}}{\frac{\pi}{4 \pi}}$} & \multirow{4}{*}{ Serviços Sociais } & \multirow{2}{*}{ Custos de produção } & & \multirow{7}{*}{$\begin{array}{l}\text { Orientada para } \\
\text { diferenciação dos } \\
\text { serviços }\end{array}$} & $\begin{array}{l}\text { Redes de } \\
\text { Informacão }\end{array}$ & Infraestrutura física \\
\hline Administração Pública e Defesa & & & & & & $\begin{array}{l}\text { Dominado por } \\
\text { fornecedor }\end{array}$ & $\begin{array}{l}\text { Pessoais dominado } \\
\text { pelos fornecedores }\end{array}$ \\
\hline Educação & & & $\begin{array}{l}\text { Agregaccão valor } \\
\text { (Universidades) }\end{array}$ & & & \begin{tabular}{|l} 
Baseado \\
Ciência \\
(Universidades) \\
e Dominado por \\
fornecedor
\end{tabular} & $\begin{array}{l}\text { Intensivos em } \\
\text { conhecimento } \\
\text { (Universidades) } \mathrm{e} \\
\text { Pessoais dominado } \\
\text { pelos fornecedores }\end{array}$ \\
\hline Saúde e Assistência Social & & & & & & \multirow{4}{*}{$\begin{array}{c}\text { Dominado pelos } \\
\text { fornecedores }\end{array}$} & \multirow{4}{*}{$\begin{array}{l}\text { Pessoais dominado } \\
\text { pelos fornecedores }\end{array}$} \\
\hline $\begin{array}{l}\text { Venda, Manutenção e Reparação de Veículos } \\
\text { Automóveis; Venda de Combustivel }\end{array}$ & & \multirow{3}{*}{$\begin{array}{l}\text { Serviços } \\
\text { Pessoais }\end{array}$} & & & & & \\
\hline Hotéis e Restaurantes & & & & & & & \\
\hline Outros Serviços Comunitários, Sociais e Pessoais & & & & & & & \\
\hline
\end{tabular}

Quadro 1 - A Literatura e a Classificação das Atividades de Serviços Segundo a World Input-Output Database

Obs.: Os segmentos com células "em branco" não foram considerados pela tipologia.

Fonte: Elaboração própria.

\section{Mudanças Recentes nas Relações nas Atividades Econômicas}

Considerando que o objetivo principal do estudo é ressaltar as relações entre as atividades de serviços e industriais, esta seção agrega a economia em três setores (Recurso Naturais; Indústria de Transformação; Construção) e divide os Serviços em quatro segmentos (Distribuição; Sociais, Pessoais; Produtivos). Essa classificação, que segue a proposta por Singelmann (1978), é adotada pelo World Input-Output Database (WIOD, 2014), fontes das estatísticas utilizadas na análise dos subitens seguintes. Ao manter essa tipologia, procura-se evitar problemas e/ou hipóteses adicionais na compatibilização dos dados. Porém, devido às suas características distintivas e importância nas economias, os Serviços Produtivos (Eletricidade, Gás e Abastecimento de Água; Intermediação Financeira; Atividades Imobiliárias; Locação de Máquinas e Equipamentos \& e Outras Atividades de Negócios) e Sociais (Correios e Telecomunicações; Administração Pública e Defesa; Educação; Saúde e Assistência Social) são aferidos de forma desagregada, ou seja, a avaliação caminha na direção da taxonomia de Castellacci (2008) - vide Quadro 1.

Dois indicadores são empregados de forma complementar na análise dos dados. O primeiro, empregado no subitem 3.1, o valor (trilhões de dólares) e a participação do valor adicionado (contribuição ao PIB) permite avaliar a dimensão dos agregados e/ou segmentos na economia. O segundo, instrumento analítico do subitem 3.2, advém do Índice de Ligação de Rasmussen-Hirschman (R-H). Elaborado a partir dos conceitos desenvolvidos por Rasmussen (1956) e Hirschman (1958), é o mais tradicional indicador para identificar os setores chaves de uma economia. Ele foi desenvolvido a partir da matriz inversa de Leontief para detectar os setores com maior poder de encadeamento, alavancagem ou impacto na economia. O R-H, que pode ser utilizado, por exemplo, como parâmetro para seleção dos "atores" de políticas de desenvolvimento, é estimado em duas 
perspectivas: (i) o índice de ligação para trás mensura o poder de indução da produção dos setores (impacto da demanda) sobre a oferta dos demais; (ii) índice de ligação para frente mede o poder do setor de criar mercados por meio da disponibilidade de oferta (GOMES, 1992; 22) ${ }^{2}$.

Guilhoto et al., (1994; 289) criticam os dois índices porque eles não levam em consideração os diferentes níveis de absorção e produção em cada setor da economia. Em outras palavras, o R-H não considera o número de interações do setor: por exemplo, se um determinado setor $i$ tem relação de valor muito elevado e concentrada apenas no setor $j$, ele poderá ter um R-H alto. Procurando contornar esse problema, a avalição do subitem 3.2 calcula os dois índices a partir do número de elos existentes entre dois setores/agregados: (i) encadeamentos a montante - mede o número de elos de um agregado/segmento da economia como demandante dos demais e; (ii) encadeamentos a jusante - mensura os vínculos de um agregado/setor como fornecedor de bens e serviços.

Assim, para cada agregado/segmento, a metodologia procura associar valor (monetário e participação relativa) adicionado, como medida de volume (direto e relativo), e o número de vínculos com outros setores da economia, como indicador ou grau de capilaridade (dispersão das relações). Se um agregado/segmento tem elevado participação no valor adicionado total e muitos elos com outras atividades, ele se destaca, respectivamente, pela sua relevância econômica e capacidade de indução para frente e/ou para trás. Além disso, se a capilaridade cresceu no período analisado (1995 e 2010), o agregado/segmento é um ator privilegiado nas mudanças recentes.

Os dois índices de capilaridade são calculados pelo método Análise de Redes, aqui empregado como uma ferramenta para medir as interrelações/dependências. Entre as suas virtudes, o método possibilita a (i) seleção pelo valor (por exemplo, eliminando fluxos pouco relevantes) e a (ii) elaboração de indicadores específicos que sumarizam as relações.

A Análise de Redes utiliza o número de linhas ou ligações da rede - elos entre nós (agregados/segmentos) -, para calcular a densidade (total) da rede, ou seja, a relação entre elos existentes e possíveis. A densidade é medida pela razão $m /(n(n-1))$, onde $n$ é o número de nós e $m$ é o número de linhas (GOYAL, 2007) ${ }^{3}$. Assim, a densidade varia no intervalo [0,1]; se a densidade é alta (próxima de 1), maior o número de ligações ou de relacionamentos e conexões entre os diferentes setores (SAVIOTTI, 2009). Neste estudo, a densidade elevada significa que uma determinada atividade da economia tem vínculos bastante diversificados ${ }^{4}$.

O método desenvolvido calcula a densidade total (vínculos reais entre todos os agregados/segmentos existentes na economia), a partir da somatória das densidades parciais, ou seja, da soma das densidades dos pares $(k, t)=\mathrm{sd}$ (serviços de distribuição), ss (serviços sociais), sp (serviços pessoais), sp (serviços produtivos), i (indústria de transformação), $\mathrm{r}$ (recursos naturais) e c (construção), com $\mathrm{k} \neq \mathrm{t}$. Assim, a densidade total pode ser descrita por:

\footnotetext{
${ }^{2}$ A forma tradicional de mensuração e análise dos setores chaves por ser encontrada em Guilhoto e Sesso Filho (2005).

${ }^{3}$ Como este estudo trabalha como um número fixo de agregados/segmentos (nós), uma mudança na densidade decorre diretamente de variações nas relações interagregados (linhas).

${ }^{4}$ Este indicadores foram inspirados no estudo de Hausmann et al. (2014) que utilizaram dados de comércio exterior para avaliar diferentes estruturas produtivas nacionais.
} 
Densidade total $=\frac{M r, t}{n(n-1)}+\frac{M i, t}{n(n-1)}+\frac{M c, t}{n(n-1)}+\frac{M s d, t}{n(n-1)}+\frac{M s s, t}{n(n-1)}+\frac{M s p, t}{n(n-1)}+\frac{\text { Mspro, } t}{n(n-1)}$

n: número de agregados/segmentos;

$\mathrm{M}_{k, t}:$ Número de linhas (elos) para trás (ILT) OU para frente (ILF) entre os pares ( $\mathrm{k}, \mathrm{t}$ ) como definido acima;

$\mathrm{M}_{k, t} /[\mathrm{n}(\mathrm{n}-1)]$ - Densidade parcial medida pelas relações entre os pares $(\mathrm{k}, \mathrm{t})$.

Como mencionado, o método adotado permite analisar separadamente os elos para frente e para trás. O primeiro (Índice de Ligação para Trás: ILT) utiliza o número de ligações (linhas) relacionadas à demanda do agregado/segmento por produtos e serviços dos demais. O segundo (Índice de Ligação para Frente: ILF), estima o número de elos (linhas) do agregado/segmento como fornecedor de bens e serviços para a economia. Em ambos os casos a análise é desenvolvida por meio das densidades definidas acima.

Por fim, foram contabilizados no número de relações interagregados apenas os fluxos intermediários superiores a US\$ 500 milhões (equivalente a US\$ 372 milhões de 1995 quando deflacionado pelo OECDindex). Exceto para o México, a restrição mantém mais de $90 \%$ do total de elos existentes nas economias da amostra ${ }^{5}$. Esse filtro permite manter os vínculos de fato relevantes e simplifica a análise dos resultados que o método oferece.

Os indicadores mencionados acima são aplicados aos anos de 1995 e 2010 nas doze maiores economias mundiais (segundo o PIB de 2011). No conjunto, segundo os dados do FMI para 2013, essas economias respondem por quase $70 \%$ do PIB global. Os países são classificados em dois grupos de acordo com a UNCTADstat (2013): desenvolvidos (PD - Alemanha, EUA, França, Itália, Japão e Reino Unido) e países em desenvolvimento (PED - Brasil, China, Coreia, Índia, México e Rússia).

\subsection{Participação no Valor Adicionado}

A Tabela 1 mostra a participação do valor adicionado dos três agregados econômicos e quatro segmentos de serviços atendidos neste estudo. Considerando que entre 1995 e 2010 o crescimento do valor adicionado nominal nos PED foi quase seis $(5,8)$ vezes maiores do que o registrado nos $\mathrm{PD}$, a diferença na capacidade de agregar valor entre os dois blocos foi reduzida de mais de seis $(6,4)$ para menos de duas vezes e meia $(2,3)$. Em suma, uma mudança extraordinária para um período tão curto. Esse desempenho contempla não apenas aspectos relativos à divisão internacional do trabalho, mas também alterações nas formas como estão vinculadas as atividades econômicas.

\footnotetext{
${ }^{5}$ Por exemplo, nos EUA e China a limitação representa menos de $1 \%$ dos fluxos intermediários.
} 


\begin{tabular}{|c|c|c|c|c|c|c|c|c|c|c|c|c|c|c|c|c|c|c|c|c|c|c|c|c|}
\hline & \multicolumn{3}{|c|}{$\begin{array}{l}\text { Valor Adicionado } \\
\text { (trilhões de US\$) }\end{array}$} & \multicolumn{3}{|c|}{$\begin{array}{c}\text { Recursos Naturais } \\
(\%)\end{array}$} & \multicolumn{3}{|c|}{$\begin{array}{c}\text { Indústria de } \\
\text { Transformação (\%) }\end{array}$} & \multicolumn{3}{|c|}{ Construção (\%) } & \multicolumn{3}{|c|}{$\begin{array}{c}\text { Serviços de } \\
\text { distribuição (\%) }\end{array}$} & \multicolumn{3}{|c|}{ Serviços Sociais $(\%)$} & \multicolumn{3}{|c|}{$\begin{array}{c}\text { Serviços Pessoais } \\
(\%)\end{array}$} & \multicolumn{3}{|c|}{$\begin{array}{c}\text { Serviços Produtivos } \\
(\%)\end{array}$} \\
\hline & 1995 & 2010 & Var & 1995 & 2010 & Var & 2010 & 1995 & Var & 1995 & 2010 & Var & 1995 & 2010 & Var & 1995 & 2010 & Var & 1995 & 2010 & Var & 1995 & 2010 & Var \\
\hline rasil & 0.67 & 1.80 & 168.0 & 6.6 & 7.3 & 11.3 & 18.6 & 16.8 & -9.9 & 5.5 & 5.7 & 4.3 & 14.2 & 15.9 & 11.6 & 19.4 & 21.3 & 9.7 & 8.2 & 7.4 & -9.4 & 27.5 & 25.6 & -6.9 \\
\hline Thina & 0.73 & 5.93 & 714.7 & 24.0 & 14.5 & -39.7 & 34.8 & 32.9 & -5.5 & 6.1 & 6.6 & 8.3 & 13.0 & 13.5 & 3.8 & 6.0 & 10.8 & 79.2 & 3.3 & 4.4 & 33.9 & 12.7 & 17.2 & 35.8 \\
\hline ndia & 0.35 & 1.56 & 347.1 & 28.0 & 19.5 & -30.3 & 18.6 & 15.3 & -17.7 & 5.1 & 8.2 & 61.3 & 17.9 & 20.9 & 17.0 & 11.2 & 13.7 & 22.3 & 4.0 & 4.4 & 8.2 & 15.2 & 18.0 & 18.3 \\
\hline ússia & 0.32 & 1.30 & 311.5 & 15.6 & 14.4 & -7.5 & 17.4 & 15.2 & -12.6 & 6.0 & 6.0 & -0.3 & 30.4 & 26.3 & -13.4 & 11.4 & 14.0 & 22.6 & 5.4 & 4.3 & -21.8 & 13.7 & 19.7 & 44.4 \\
\hline léxico & 0.31 & 0.99 & 220.2 & 12.9 & 12.1 & -6.6 & 20.0 & 17.6 & -11.9 & 4.7 & 6.6 & 40.7 & 21.2 & 22.8 & 7.7 & 12.0 & 15.3 & 26.7 & 5.7 & 4.9 & -13.2 & 23.5 & 20.8 & -11.8 \\
\hline Coreia & 0.48 & 0.91 & 89.5 & 6.6 & 2.9 & -57.1 & 27.2 & 30.2 & 11.2 & 10.1 & 6.3 & -37.9 & 14.2 & 12.6 & -11.4 & 14.3 & 18.7 & 30.2 & 6.5 & 6.4 & -0.9 & 21.1 & 23.0 & 9.2 \\
\hline Média & 0.48 & 2.08 & 337.6 & 15.6 & 11.8 & -24.6 & 22.8 & 21.3 & -6.3 & 6.2 & 6.6 & 5.1 & 18.5 & 18.7 & 1.0 & 12.4 & 15.6 & 25.9 & 5.5 & 5.3 & -4.0 & 18.9 & 20.7 & 9.4 \\
\hline UA & 7.41 & 14.51 & 95.8 & 2.3 & 2.7 & 18.3 & 15.5 & 11.8 & -23.9 & 4. & 3.7 & -11.3 & 16.8 & 14.7 & -12.2 & 22.7 & 23.7 & 4.4 & 7. & 7.7 & 3.1 & 31.1 & 35.7 & 14.7 \\
\hline Japão & 5.24 & 5.37 & 2.5 & 2.0 & 1.5 & -26.4 & 22.6 & 18.9 & -16.2 & 8.2 & 5.9 & -28.7 & 18.6 & 16.2 & -13.0 & 15.4 & 20.4 & 32.1 & 8.5 & 8.9 & 4.2 & 24.6 & 28.3 & 15.0 \\
\hline Alemanha & 2.28 & 2.98 & 31.0 & 1.9 & 1.1 & -42.6 & 22.7 & 20.9 & -7.9 & 6.8 & 4.2 & -38.7 & 12.7 & 12.4 & -2.4 & 19.8 & 20.1 & 1.3 & 7.5 & 8.0 & 6.5 & 28.7 & 33.4 & 16.6 \\
\hline França & 1.40 & 2.33 & 66.9 & 3.7 & 2.2 & -40.5 & 14.3 & 10.4 & -27.1 & 5.7 & 6.1 & 8.2 & 13.2 & 13.4 & 1.3 & 23.0 & 24.5 & 6.3 & 7.1 & 7.7 & 8.1 & 32.9 & 35.6 & 8.3 \\
\hline Itália & 1.01 & 1.82 & 81.0 & 3.9 & 2.2 & -42.3 & 22.4 & 16.7 & -25.7 & 5.4 & 6.1 & 13.1 & 17.2 & 14.6 & -15.4 & 17.7 & 20.1 & 13.9 & 8.7 & 9.0 & 3.3 & 24.8 & 31.4 & 26.6 \\
\hline Reino Unido & 1.04 & 2.05 & 96.6 & 4.3 & 3.2 & -24.6 & 21.0 & 11.4 & -46.0 & 5.0 & 5.8 & 15.6 & 14.4 & 13.3 & -7.8 & 20.3 & 19.9 & -1.9 & 8.0 & 9.6 & 20.0 & 27.0 & 36.8 & 36.5 \\
\hline Média PD & 3.06 & 4.84 & 58.2 & 3.0 & 2.2 & -28.2 & 19.8 & 15.0 & -24.0 & 5.9 & 5.3 & -10.0 & 15.5 & 14.1 & -9.0 & 19.8 & 21.4 & 8.2 & 7.9 & 8.5 & 7.5 & 28.2 & 33.5 & 19.0 \\
\hline édia Total & 1.77 & 3.46 & 95.8 & 9.3 & 7.0 & \begin{tabular}{|l|}
-25.2 \\
\end{tabular} & 21.3 & 18.2 & -14.5 & 6.1 & 5.9 & -2.2 & 17.0 & 16.4 & -3.6 & 16.1 & 18.5 & 15.0 & 6.7 & 6.9 & 2.8 & 23.6 & 27.1 & 15.2 \\
\hline
\end{tabular}

Tabela 1 - Participação dos Agregados no Valor Adicionado dos Países Selecionados (\%) Obs.: Var: variação no período; PED: países em desenvolvimento; PD: países desenvolvidos. Para a participação no VA não foram realizados cortes relativos aos valores.

Fonte: World Input-Output Database (WIOD). Elaboração própria.

A Tabela 1 mostra também a queda da participação da indústria de transformação no total do valor adicionado em quase todos os países - exceto da Coreia (11\%). Entre os PED as reduções foram menos acentuadas (média de $-6 \%$ ), quando comparados aos PD (-24\%). A perda de participação em ambos os grupos de países tem como contrapartida principal o aumento dos Serviços Sociais (Correios e Telecomunicações, Administração Pública e Defesa e Educação - 26\% e 8\%, respectivamente) e Produtivos nas economias (9\% e 19\%) - exceto Brasil (-7\%) e México (-12\%) -, cujas características são muito distintas (vide Quadro 1). As tabelas 2 e 3 permitem avaliar esse dois casos de forma desagregada.

A participação dos Serviços Sociais (média de 19\% do total) no valor adicionado cresceu em toda amostra (exceto Reino Unido), refletindo o aumento de componentes da estrutura política e social na economia. Independente do bloco de países, em geral, o segmento de Administração Pública e Defesa representa a maior contribuição individual ao valor adicionado para esse grupo ${ }^{6}$. O segundo segmento em termos de agregação de valor parece ser um diferencial entre os PD e PED. Se nos primeiros países a Saúde e Assistência Social (contribuição média de 7\%) são mais relevantes (estado social mais desenvolvido, população mais idosa, etc), nos PED esses serviços são superados pela Educação (4\%) - vide Tabela 2.

\footnotetext{
${ }^{6}$ Em particular, o Brasil se diferencia dos demais países em razão: i) elevada participação dos Serviços Sociais no total dos serviços - similar à média (21\%) dos PD em 2010; ii) a Administração Pública e Defesa apresenta a maior participação relativa dentro do agregado (10\%), superior à média dos PED (6\%) e PD (7\%).
} 


\begin{tabular}{|c|c|c|c|c|c|c|c|c|c|c|c|c|c|c|c|c|c|c|c|c|c|}
\hline \multirow{2}{*}{ Países em Desenvolvimento } & \multicolumn{3}{|c|}{ Brasil } & \multicolumn{3}{|c|}{ China } & \multicolumn{3}{|c|}{ Índia } & \multicolumn{3}{|c|}{ Rússia } & \multicolumn{3}{|c|}{ México } & \multicolumn{3}{|c|}{ Coreia } & \multicolumn{3}{|c|}{ Média PeD } \\
\hline & 1995 & 2010 & Var & 1995 & 2010 & Var & 1995 & 2010 & Var & 1995 & 2010 & Var & 1995 & 2010 & Var & 1995 & 2010 & Var & 1995 & 2010 & Var \\
\hline Correios e Telecomunicações & 0.7 & 2.0 & 188.9 & 0.9 & 2.5 & 196.9 & 1.3 & 1.4 & 10.0 & 1.5 & 2.2 & 47.1 & 2.0 & 2.9 & 48.3 & 1.9 & 1.8 & -1.1 & 1.4 & 2.2 & 58.4 \\
\hline Administração Pública e Defesa & 9.5 & 10.1 & 6.5 & 2.2 & 3.6 & 62.8 & 5.4 & 6.4 & 18.5 & 4.3 & 5.6 & 30.7 & 3.3 & 4.3 & 33.5 & 5.4 & 6.2 & 14.2 & 5.0 & 6.1 & 20.6 \\
\hline Educação & 5.3 & 5.1 & -3.1 & 2.1 & 3.1 & 49.4 & 3.2 & 4.3 & 31.8 & 3.1 & 2.7 & -11.6 & 4.1 & 5.0 & 20.7 & 4.9 & 6.2 & 24.7 & 3.8 & 4.4 & 15.9 \\
\hline Saúde e Assistência Social & 3.9 & 4.0 & 2.4 & 0.9 & 1.6 & 76.5 & 1.3 & 1.6 & 26.0 & 2.6 & 3.5 & 35.4 & 2.7 & 3.0 & 11.6 & 2.1 & 4.5 & 111.5 & 2.3 & 3.0 & 34.9 \\
\hline \multirow{2}{*}{ Países Desenvolvidos } & \multicolumn{3}{|c|}{ EUA } & \multicolumn{3}{|c|}{ Japão } & \multicolumn{3}{|c|}{ Alemanha } & \multicolumn{3}{|c|}{ França } & \multicolumn{3}{|c|}{ Itália } & \multicolumn{3}{|c|}{ Reino Unido } & \multicolumn{3}{|c|}{ Média PD } \\
\hline & 1995 & 2010 & Var & 1995 & 2010 & Var & 1995 & 2010 & Var & 1995 & 2010 & Var & 1995 & 2010 & Var & 1995 & 2010 & Var & 1995 & 2010 & Var \\
\hline Correios e Telecomunicações & 3.1 & 2.5 & -18.9 & 1.8 & 2.2 & 24.4 & 2.4 & 1.7 & -30.6 & 2.2 & 2.0 & -9.4 & 1.7 & 2.0 & 17.8 & 2.8 & 2.6 & -6.6 & 2.3 & 2.1 & -7.1 \\
\hline Administração Pública e Defesa & 12.5 & 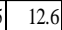 & 1.2 & 5.9 & 8.7 & 47.8 & 6.8 & 5.9 & -12.1 & 7.8 & 7.7 & -0.5 & 6.1 & 6.9 & 11.9 & 5.9 & 4.8 & -18.2 & 7.5 & 7.8 & 3.9 \\
\hline Educação & 0.8 & 1.0 & 29.0 & 4.0 & 4.0 & -2.1 & 4.3 & 4.6 & 5.3 & 5.6 & 5.5 & -1.3 & 5.0 & 4.9 & -0.9 & 5.5 & 5.4 & -0.7 & 4.2 & 4.2 & 0.9 \\
\hline Saúde e Assistência Social & 6.3 & 7.5 & 19.0 & 3.7 & 5.5 & 47.8 & 6.3 & 7.9 & 25.3 & 7.5 & 9.3 & 23.4 & 4.9 & 6.3 & 30.2 & 6.2 & 7.1 & 14.6 & 5.8 & 7.3 & 24.9 \\
\hline
\end{tabular}

Tabela 2 - Participação Relativa dos Serviços Sociais no Total do Valor Adicionado dos Países Selecionados (\%)

Obs.: Var: variação no período; PED: países em desenvolvimento; PD: países desenvolvidos.

Fonte: World Input-Output Database (WIOD). Elaboração própria.

Em 2010, os Serviços Produtivos responderam pela maior parcela do valor adicionado entre todos os agregados propostos para este estudo: $21 \%$ nos PED e $34 \%$ nos PD. No período analisado, a participação dessas atividades nas economias cresceu em todos os países da amostra (exceto México), cerca de 9\% e 19\%, respectivamente - vide tabelas 1 e 2.

Os três segmentos mais importantes desses serviços são Intermediação Financeira, Atividades Imobiliárias e Locação de Máquinas e Equipamentos e Outras Atividades de Negócios. Se entre os PED eles têm pesos, em geral, similares na estrutura econômica (média entre 6\% e 7\%), nos PD prevalecem os dois últimos (média aproximada de 13\%). Além dessa diferença, se consideradas também as taxas de crescimento, pode-se aventar uma tendência de predomínio do último segmento.

\begin{tabular}{|c|c|c|c|c|c|c|c|c|c|c|c|c|c|c|c|c|c|c|c|c|c|}
\hline \multirow{2}{*}{ Países em Desenvolvimento } & \multicolumn{3}{|c|}{ Brasil } & \multicolumn{3}{|c|}{ China } & \multicolumn{3}{|c|}{ Índia } & \multicolumn{3}{|c|}{ Rússia } & \multicolumn{3}{|c|}{ México } & \multicolumn{3}{|c|}{ Coreia } & \multicolumn{3}{|c|}{ Média PeD } \\
\hline & 95 & \begin{tabular}{|l|}
2010 \\
\end{tabular} & Var & 1995 & 2010 & \begin{tabular}{|l|} 
Var \\
\end{tabular} & 1995 & 2010 & \begin{tabular}{|l|l|} 
Var \\
\end{tabular} & 1995 & 2010 & \begin{tabular}{|l|l|} 
Var \\
\end{tabular} & 1995 & 2010 & Var & 1995 & 2010 & Var & 19952 & 2010 & Var \\
\hline Eletricidade, & 60 & 3.12 & 19.9 & 2.19 & 2.76 & 26.3 & 2.67 & 1.65 & \begin{tabular}{|l|}
-38.3 \\
\end{tabular} & 4.54 & 2.87 & \begin{tabular}{|l|}
-36.9 \\
\end{tabular} & 1.22 & 1.20 & -1.8 & 1.99 & 2.07 & 37 & 2.54 & 2.28 & 0.2 \\
\hline Interm & 03 & .17 & \begin{tabular}{|l|}
-20.6 \\
\end{tabular} & 4.60 & 5.21 & 13.3 & 36 & 5.78 & 7.8 & 66 & .50 & 68.9 & 6.45 & 59 & -28.8 & 6.08 & .82 & \begin{tabular}{|l|}
12.1 \\
\end{tabular} & .70 & 68 & 0.3 \\
\hline Ativid & 34 & 8.29 & -7.2 & 3.87 & 5.67 & 46.5 & 6.02 & 5.66 & -6.0 & 3.07 & 13 & 66.8 & 11.61 & 92 & -23.2 & 7.71 & .11 & -7.8 & 6.87 & 80 & 1.1 \\
\hline Loca & 91 & 6.99 & 1.1 & 2.02 & 3.58 & 77.2 & 1.18 & 4.94 & 319.3 & 3.39 & 7.25 & 113.6 & 4.26 & 6.05 & 42.2 & 5.27 & 7.00 & 32.9 & 3.84 & 5.97 & 5.5 \\
\hline \multirow{2}{*}{ íses Deser } & \multicolumn{3}{|c|}{ EUA } & \multicolumn{3}{|c|}{ Japão } & \multicolumn{3}{|c|}{ Alemanha } & \multicolumn{3}{|c|}{ França } & \multicolumn{3}{|c|}{ Itália } & \multicolumn{3}{|c|}{ Reino Unido } & \multicolumn{3}{|c|}{ Média PD } \\
\hline & 1995 & 2010 & Var & 1995 & 2010 & Var & 1995 & 2010 & Var & 1995 & 2010 & Var & 1995 & 2010 & Var & 1995 & 2010 & Var & 19952 & 2010 & Var \\
\hline Eletrici & 2.24 & 1.80 & \begin{tabular}{|l|}
-19.7 \\
\end{tabular} & 2.63 & 2.47 & -5.8 & 2.17 & 2.85 & 31.4 & 4.32 & 1.65 & -61.7 & 2.24 & 2.28 & 1.9 & 2.33 & 2.24 & -4.0 & 2.65 & 2.22 & -16.5 \\
\hline Interm & 7.28 & 9.44 & 29.7 & 5.97 & 5.13 & -14.0 & 4.62 & 4.52 & -2.1 & 4.66 & 5.48 & 17.7 & 4.75 & 5.46 & 15.0 & 6.44 & 8.53 & 32.4 & \begin{tabular}{l|l|}
5.62 \\
\end{tabular} & 6.43 & 14.4 \\
\hline & 02 & 10.79 & -2.1 & 10.30 & 12.72 & 23.5 & 11.24 & 12.27 & 9.2 & \begin{tabular}{|l|}
11.58 \\
\end{tabular} & 14.39 & 24.3 & 10.75 & \begin{tabular}{|l|}
14.16 \\
\end{tabular} & 31.7 & 7.95 & 8.88 & 11.8 & 10.47 & 12.20 & 16. \\
\hline ocação de M \& Eq e & 0.57 & 13.64 & 29.1 & 5.69 & 7.93 & 39.4 & 10.62 & 13.77 & 29.6 & 12.37 & 14.12 & 14.2 & 7.08 & 9.52 & 34.5 & 10.25 & 17.18 & 67.6 & 9.43 & 12.69 & 34. \\
\hline
\end{tabular}

Tabela 3 - Participação dos Serviços Produtivos no Total do Valor Adicionado dos Países

Selecionados $(\%)$

Obs.: Var: variação no período; PED: países em desenvolvimento; PD: países desenvolvidos.

Fonte: World Input-Output Database (WIOD). Elaboração própria.

Os serviços de Locação de Máquinas, Equipamentos e Outras Atividades de Negócios são aqueles que reúnem funções terceirizadas e/ou com maior capacidade de apoio às inovações. Nesse segmento estão as contribuições mais significativas para o valor adicionado total entre os PED (média de 3,8\% em 1995 e 6,0\% em 2010, aumento de 55,5\%) e PD (média de 9,43\% em 1995 e 12,7\% em 2010, aumento de 34,6). Além das participações diferenciadas (cerca de metade entre os dois blocos), nos PD essas atividades já se apresentavam elevadas desde o primeiro período. Esse aspecto parece reforçar a tese de terceirização e especialização mais acentuada nesses últimos países do que nos PED (SCHETTKAT e YOCARINI, 2005; OCDE, 2013). Ressalte-se que o Brasil e o México são os únicos países da amostra com taxas negativas de crescimento do valor adicionado nessas atividades e também na indústria de transformação, em parte 
compensadas (diferenças das médias) por Recurso Naturais e Construção, respectivamente. Em outras palavras, os dois países parecem divergir da tendência da amostra.

Em suma, serviços de Locação de Máquinas, Equipamentos e Outras Atividades de Negócios são os mais relevantes da amostra, representando cerca de $6 \%$ do valor adicionado nos PED e 13\% nos PD em 2010. Além disso, as taxas de crescimentos do valor adicionado estão entre as mais elevadas entre as atividades tratadas neste estudo. Assim, é possível intuir que o crescimento da participação das atividades de serviços é assimétrica (reforçando as heterogeneidades internas) e concentrada especialmente em Serviços Sociais (relativo ao papel dos estados nacionais e mudanças nas características da população) e nos sérvios vinculados à indústria de transformação. Esta última tendência parece reforçar a tese que associa a transferência de funções industriais e crescente especialização desses serviços. Em outras palavras, o papel atual da indústria se caracteriza não apenas como importante demandante, mas também como indutor da especialização e produtividade dos serviços especializados ${ }^{7}$. A seguir são examinados complementarmente os vínculos entre as diferentes atividades selecionadas para este estudo, em especial serviços-indústria de transformação.

\subsection{Interações entre as Atividades de Serviços e Industriais}

Considerando que a economia é tratada como um "sistema fechado", é inerente à concepção das matrizes de insumo-produto que as duas densidades totais relativas aos índices de ligação para trás e para frente sejam iguais quando calculadas de forma agregada para cada país. Todavia, o interesse deste estudo está nas diferenças surgidas na decomposição desses índices, ou seja, nas densidades parciais. A primeira coluna da Tabela 4 mostra o valor da densidade total (elos existentes) em 1995 e 2010. As demais colunas exibem as densidades parciais em termos porcentuais, permitindo comparar a contribuição/potencial de cada agregado/segmento para o total de cada país ou bloco econômico, independentemente do tamanho da economia (dimensão dada pela densidade e valor adicionado).

Assim como ocorreu com o valor adicionado, a densidade total dos PED cresceu substancialmente mais do que nos PD, porém as diferenças ainda são significativas - $25 \%$ maior. Em termos médios, houve um movimento de convergência entre os dois blocos, mas algumas desigualdades persistem, seja decorrente dos problemas ligados ao desenvolvimento nacional (México) ou da estrutura econômica (Rússia, baseada em serviços de distribuição), seja espelhando o processo de "desindustrialização" (Reino Unido).

Em 2010, os elos indústria de transformação com as demais representaram cerca de 40\% do total - vide Índice de Ligação para Trás (ILT) na parte superior da Tabela 4. Apesar da pequena redução $(-4 \%)$ da parcela dessa atividade na contribuição para a densidade total ${ }^{8}$, ela continua determinante para impulsionar as economias da amostra.

\footnotetext{
${ }^{7}$ Há resultados inversos nos serviços pessoais entre PED (média de 5,5\% e 5,3\%, respectivamente em 1995 e 2010) e PD (média de 7,9\% e 8,5\%, idem). Esse diferencial pode ser explicado pelo diferencial da renda entre os dois blocos (hipótese de CLARK, 1940) e também pelo aumento da qualidade dos serviços oferecidos nos PD (PARK e CHAN, 1989), em geral, fruto da diferenciação (SAVONA; 2008).

${ }^{8}$ Recursos Naturais e Construção foram os agregados que tiveram as maiores reduções na participação relativa, $-12 \%$ e $-14 \%$ na média, respectivamente. No primeiro caso, o Brasil $(17,4 \%)$ é a primeira exceção (resultado da demanda chinesa) e, no segundo, estão os países em desenvolvimento, EUA (4,8\%), Japão $(13,4 \%)$ e Reino Unido (4\%) - possivelmente como reflexos da bolha imobiliária.
} 
Nos PD a média ILT da indústria de transformação foi reduzida para 38,4 e nos PED para $42,7 \% \%$ (Coreia, 1,7, e Rússia, 8\%, registraram variações positivas).

Esta redução não pode ser considerada uma tendência geral, relacionada aos PD e/ou diretamente com a perda de participação da indústria no valor adicionado. Houve casos em que o potencial de indução da indústria diminui - EUA (ILT de 37,1\%, queda de $-7,5 \%)$ e Reino Unido $(28,0 \% ;-22,9 \%)$ - e outros que aumentou - França $(35,9 \%$; $11,5 \%)$ e Alemanha $(43,4 \% ; 2,6 \%)$. Em todos esses exemplos houve redução da participação da indústria no valor adicionado, porém os percentuais foram muito distintos $(-46 \%,-23,9 \%,-27,1 \%$ e $-7,9 \%$, respectivamente; vide Tabela 1). Em outras palavras, não é possível estabelecer relação direta entre queda no ILT industrial e valor adicionado.

Além disso, os elos industriais no Japão, Alemanha e França, por exemplo, são em maior número do que em alguns em PED, como México (37,9\%), Brasil (39,2\% em 2010) e Rússia (30,1\%). Assim, a densidade industrial não é exclusividade de um ou outro bloco de países, mas de características estruturais das economias nacionais.

Entre os PED, os países asiáticos merecem destaque em relação aos elos para trás da indústria. A Índia apresenta o maior ILT entre os países analisados (55,9\% em 2010), mesmo com relativamente baixo valor agregado industrial (15,2\% em 2010). Por outro lado, a Coreia combina capacidade de geração de valor no setor secundário $(30,2 \% \mathrm{em}$ 2010, segundo maior da amostra e variação positiva) e alto potencial de indução (ao redor de $49 \%$ nos dois anos). Na China, é elevado tanto o valor adicionado (32,9\% em 2010), quanto potencial de indução na indústria (ILT de 48\% em 1995 para 44,1\% em 2010), entre os maiores da amostra ${ }^{9}$. Alguns desses resultados parecem apontar para uma situação aparentemente paradoxal: como conciliar a redução do valor adicionado industrial e aumento dos vínculos (indução) dessa atividade com as demais? As respostas estão a seguir.

\footnotetext{
${ }^{9}$ Esse último percentual é explicado em parte pelo aumento da participação dos Serviços Sociais $(62 \%)$ e Pessoais $(72,8 \%)$, ou seja, aspecto natural para um país marcado por uma economia em forte crescimento e carências relevantes nesses serviços.
} 


\begin{tabular}{|c|c|c|c|c|c|c|c|c|c|c|c|c|c|c|c|c|c|c|c|c|c|c|c|c|}
\hline \multirow[b]{2}{*}{ Trás - ILT } & \multicolumn{3}{|c|}{ Densidade (0-1) } & \multicolumn{3}{|c|}{$\begin{array}{c}\text { Recursos Naturais } \\
(\%)\end{array}$} & \multicolumn{3}{|c|}{$\begin{array}{c}\text { Indústria de } \\
\text { Transformaçãa (\%) }\end{array}$} & \multicolumn{3}{|c|}{ Construção (\%) } & \multicolumn{3}{|c|}{$\begin{array}{c}\text { Serviços de } \\
\text { distribuição }(\%)\end{array}$} & \multicolumn{3}{|c|}{ Serviços Sociais $(\%)$} & \multicolumn{3}{|c|}{ Serviços Pessoais (\%) } & \multicolumn{3}{|c|}{$\begin{array}{l}\text { Serviços Produtivos } \\
(\%)\end{array}$} \\
\hline & 1995 & 2010 & Var & 1995 & 2010 & Var & 1995 & 2010 & Var & 1995 & 2010 & Var & 1995 & 2010 & Var & 1995 & 2010 & Var & 1995 & 2010 & Var & 1995 & 2010 & Var \\
\hline Brasil & 0.25 & 0.38 & 51.4 & 6.4 & 7.5 & 17.4 & 41.1 & 39.2 & -4.7 & 6.1 & 4.7 & -22.3 & \begin{tabular}{|l|l|}
10.7 \\
\end{tabular} & 13.2 & 23.3 & 15.7 & 16.0 & 2.1 & 7.9 & 8.0 & 2.1 & 12.1 & 11.3 & -6.8 \\
\hline thina & 0.34 & 0.71 & 110.8 & 8.7 & 6.9 & -20.9 & 48.0 & 44.1 & -8.3 & 5.5 & 3.8 & -32.2 & 14.2 & 14.3 & 0.1 & 8.2 & 13.3 & 62.2 & 3.7 & 6.4 & 72.8 & 11.6 & 11.4 & -1.9 \\
\hline ndia & 0.14 & 0.27 & 93.6 & 7.0 & 6.6 & -6.1 & 56.7 & 55.9 & -1.4 & 8.3 & 6.3 & -24.5 & 12.7 & 13.5 & 5.9 & 2.5 & 4.9 & 93.7 & 4.5 & 3.3 & -26.2 & 8.3 & 9.5 & 15.2 \\
\hline Rússia & 0.13 & 0.33 & 155.1 & 12.2 & 8.3 & -32.5 & 27.9 & 30.1 & 8.0 & 6.8 & 6.1 & -9.8 & 22.4 & 20.5 & -8.5 & 14.3 & 13.1 & -8.5 & 2.7 & 5.9 & 115.6 & 13.6 & 16.0 & 17.6 \\
\hline México & 0.08 & 0.18 & 122.5 & 10.1 & 9.1 & -10.1 & 44.9 & 37.9 & -15.7 & 9.0 & 7.6 & -15.7 & 13.5 & 14.6 & 8.6 & 5.6 & 15.2 & 169.7 & 4.5 & 3.5 & -21.3 & 12.4 & 12.1 & -1.9 \\
\hline Coreia & 0.17 & 0.25 & 40.8 & 2.0 & 2.5 & 24.3 & 48.5 & 49.3 & 1.7 & 9.2 & 6.2 & -32.9 & 14.3 & 12.7 & -11.2 & 7.7 & 11.6 & 51.5 & 8.2 & 7.2 & -11.2 & 10.2 & 10.5 & 3.0 \\
\hline Média P & 0.19 & 0.35 & 90.4 & 7.8 & 6.8 & -12.1 & 44.5 & 42.7 & -4.0 & 7.5 & 5.8 & -22.9 & 14.7 & 14.8 & 1.0 & 9.0 & 12.3 & 37.1 & 5.2 & 5.7 & 9.4 & 11.4 & 11.8 & 3.9 \\
\hline EUA & 0.66 & 0.63 & -4.6 & 5.9 & 5.8 & -2.3 & 40.2 & 37.1 & -7.5 & 3.6 & 3.8 & 4.8 & 15.4 & 16.8 & 9.4 & 12.9 & 14.4 & 11.4 & 10.2 & 10.7 & 4.8 & 11.7 & 11.3 & -3.6 \\
\hline apão & 0.63 & 0.56 & -11.8 & 4.6 & 4.5 & -3.8 & 41.7 & 39.8 & -4.6 & 4.2 & 4.8 & 13.4 & 15.4 & 15.3 & -0.1 & 12.7 & 12.9 & 2.1 & 9.9 & 10.7 & 8.6 & 11.5 & 12.0 & 3.7 \\
\hline Alemanha & 0.44 & 0.41 & -7.1 & 5.5 & 3.3 & -40.2 & 43.4 & 44.6 & 2.6 & 5.1 & 4.8 & -5.3 & 13.9 & 15.0 & 7.6 & 12.1 & 12.8 & 5.8 & 9.1 & 7.6 & -16.3 & 10.9 & 12.0 & 9.6 \\
\hline França & 0.34 & 0.35 & 4.3 & 4.8 & 3.6 & -25.4 & 35.9 & 40.1 & 11.5 & 5.6 & 5.4 & -4.1 & 14.6 & 14.3 & -2.3 & 13.3 & 12.5 & -6.0 & 11.4 & 10.5 & -8.5 & 14.4 & 13.8 & -4.1 \\
\hline tália & 0.36 & 0.41 & 14.0 & 2.2 & 2.4 & 7.2 & 42.4 & 41.0 & -3.1 & 5.9 & 5.2 & -12.3 & 20.2 & 18.6 & -8.0 & 9.9 & 10.6 & 7.4 & 10.3 & 10.8 & 4.4 & 9.1 & 11.4 & 25.6 \\
\hline Reino Unido & 0.30 & 0.29 & -3.8 & 4.4 & 4.6 & 4.0 & 36.3 & 28.0 & -22.9 & 5.0 & 5.2 & 4.0 & 14.0 & 16.1 & 14.8 & 16.7 & 18.5 & 11.2 & 10.8 & 13.1 & 20.8 & 12.9 & 14.6 & 13.4 \\
\hline Média PD & 0.46 & 0.44 & -3.0 & 4.6 & 4.0 & -12.4 & 40.0 & 38.4 & -3.9 & 4.9 & 4.8 & -1.0 & 15.6 & 16.0 & 2.8 & 12.9 & 13.6 & 5.5 & 10.3 & 10.6 & 2.6 & 11.8 & 12.5 & 6.4 \\
\hline Média Total & 0.32 & 0.40 & 24.0 & 6.2 & 5.4 & -12.2 & 42.2 & 40.6 & -3.9 & 6.2 & 5.3 & -14.2 & 15.1 & 15.4 & 1.9 & 11.0 & 13.0 & 18.5 & 7.8 & 8.1 & 4.9 & 11.6 & 12.2 & 5.2 \\
\hline Frente - ILF & 1995 & 2010 & Var & 1995 & 2010 & Var & 2010 & 1995 & Var & 1995 & 2010 & Var & 1995 & 2010 & Var & 1995 & 2010 & Var & 1995 & 2010 & Var & 1995 & 2010 & Var \\
\hline Brasil & 0.25 & 0.38 & 51.4 & 3.9 & 3.3 & -16.0 & 30.4 & 32.5 & 7.2 & 1.8 & 1.9 & 5.7 & 23.6 & 23.6 & 0.1 & 1.4 & 5.7 & 296.2 & 11.4 & 9.9 & -13.3 & 27.5 & 23.1 & -16.0 \\
\hline China & 0.34 & 0.71 & 110.8 & 6.9 & 5.0 & -27.0 & 49.3 & 45.4 & -7.9 & 1.8 & 1.5 & -18.7 & 18.7 & 18.0 & -3.8 & 1.6 & 7.6 & 382.2 & 5.0 & 7.5 & 49.8 & 16.6 & 14.9 & -10.4 \\
\hline Índia & 0.14 & 0.27 & 93.6 & 8.3 & 4.6 & -44.4 & 31.2 & 36.5 & 17.0 & 2.5 & 7.6 & 197.0 & 25.5 & 23.4 & -8.3 & 1.3 & 4.3 & 235.7 & 3.8 & 5.3 & 37.7 & 27.4 & 18.4 & -32.7 \\
\hline Rússia & 0.13 & 0.33 & 155.1 & 7.5 & 4.3 & -43.0 & 23.8 & 33.9 & 42.2 & 0.7 & 2.4 & 252.8 & 38.8 & 24.5 & -36.7 & 3.4 & 8.3 & 143.0 & 4.8 & 6.7 & 40.0 & 21.1 & 20.0 & -5.2 \\
\hline México & 0.08 & 0.18 & 122.5 & 9.0 & 5.1 & -43.8 & 23.6 & 27.3 & 15.6 & 0.0 & 0.0 & 0.0 & 23.6 & 25.8 & 9.2 & 2.2 & 5.1 & 124.7 & 1.1 & 2.0 & 79.8 & 40.4 & 34.8 & -13.8 \\
\hline Coreia & 0.17 & 0.25 & 40.8 & 3.6 & 1.8 & -49.3 & 39.8 & 40.2 & 1.1 & 1.5 & 1.1 & -29.0 & 16.3 & 18.5 & 13.2 & 2.6 & 2.9 & 13.6 & 3.1 & 6.5 & 113.0 & 33.2 & 29.0 & -12.6 \\
\hline Média PeD & 0.19 & 0.35 & 90.4 & 6.5 & 4.0 & -38.5 & 33.0 & 36.0 & 9.0 & 1.4 & 2.4 & 72.1 & 24.4 & 22.3 & -8.7 & 2.1 & 5.6 & 170.6 & 4.9 & 6.3 & 29.7 & 27.7 & 23.4 & -15.6 \\
\hline EUA & 0.66 & 0.63 & -4.6 & 3.4 & 4.4 & 30.0 & 38.9 & 37.3 & -4.3 & 3.5 & 3.8 & 8.8 & 18.1 & 18.6 & 3.2 & 9.3 & 9.0 & -2.8 & \begin{tabular}{|l|}
10.1 \\
\end{tabular} & 9.7 & -3.6 & \begin{tabular}{|l}
16.7 \\
\end{tabular} & 17.1 & 2.3 \\
\hline Japão & 0.63 & 0.56 & -11.8 & 2.4 & 2.7 & 13.4 & 38.3 & 37.2 & -2.8 & 3.7 & 3.8 & 4.7 & 19.2 & 18.8 & -1.6 & 6.8 & 6.5 & -3.1 & 12.8 & 12.6 & -1.5 & 16.9 & 18.2 & 7.7 \\
\hline Alemanha & 0.44 & 0.41 & -7.1 & 3.0 & 2.2 & -28.3 & 32.3 & 28.7 & -11.2 & 5.1 & 4.3 & -13.9 & 18.4 & 21.7 & 18.3 & 6.7 & 8.3 & 23.9 & 10.5 & 9.6 & -8.9 & 24.0 & 25.2 & 4.9 \\
\hline França & 0.34 & 0.35 & 4.3 & 3.2 & 2.0 & -36.1 & 24.5 & 27.0 & 10.5 & 2.9 & 2.8 & -4.1 & 25.3 & 24.5 & -3.1 & 10.9 & 6.9 & -36.8 & 6.6 & 11.2 & 68.8 & 26.6 & 25.5 & -4.1 \\
\hline Itália & 0.36 & 0.41 & 14.0 & 2.2 & 1.9 & -12.3 & 32.3 & 31.5 & -2.3 & 4.9 & 4.5 & -7.9 & 22.9 & 22.0 & -3.8 & 3.2 & 4.3 & 34.9 & 11.8 & 12.3 & 4.1 & 22.7 & 23.3 & 2.9 \\
\hline Reino Unido & 0.30 & 0.29 & -3.8 & 1.5 & 1.5 & 4.0 & 26.0 & 16.1 & -38.1 & 3.2 & 4.3 & 32.3 & 24.3 & 28.0 & 15.2 & 7.3 & 8.2 & 12.3 & 8.8 & 11.6 & 31.7 & 28.9 & 30.4 & 5.0 \\
\hline Média PD & 0.46 & 0.44 & -3.0 & 2.6 & 2.5 & -5.7 & 32.1 & 29.6 & -7.5 & 3.9 & 3.9 & 1.3 & 21.3 & 22.3 & 4.4 & 7.4 & 7.2 & -2.0 & \begin{tabular}{|l|l|} 
& 10.1 \\
\end{tabular} & 11.2 & 10.5 & 22.6 & 23.3 & 2.9 \\
\hline Média Total & 0.32 & 0.40 & 24.0 & 4.6 & 3.2 & -29.1 & 32.5 & 32.8 & 0.8 & 2.6 & 3.2 & 20.1 & 22.9 & 22.3 & -2.6 & 4.7 & 6.4 & 36.1 & \begin{tabular}{|l|}
7.5 \\
\end{tabular} & 8.7 & 16.7 & \begin{tabular}{|l|}
25.2 \\
\end{tabular} & 23.3 & -7.3 \\
\hline
\end{tabular}

Tabela 4 - Participação dos Agregados na Densidade Total dos Países Selecionados (\%) Obs.: Var: variação no período; PED: países em desenvolvimento; PD: países desenvolvidos.

Fonte: World Input-Output Database (WIOD). Elaboração própria.

Assim como na indústria de transformação, a capacidade de indução nos segmentos do terciário variou pouco entre os dois anos, porém, ao contrário, de forma positiva. Os Serviços de Distribuição mantiveram a mais alta participação entre os grupos de serviços, mas a alteração no período foi reduzida na maioria dos países (média da participação total de 15,1\% em 1995 para 15,4\% em 2010). Esse resultado parece coerente, pois a atividade é fundamental para inúmeros setores da economia e há muito foram transferidas para o terciário ${ }^{10}$.

As principais alterações nos ILT do setor terciário ocorreram nos Serviços Sociais $(18,5 \%)$ e Produtivos $(5,2 \%)$, os primeiros especialmente nos PED $(37,1 \%)$ e os últimos nos PD $(6,4 \%)$ - vide Tabela 4. Assim, ambos tornaram-se similares aos serviços de distribuição em termos de contribuição ao total das densidades para trás $(14 \%, 12 \%$ e $15 \%$, respectivamente). Acima foi mencionado a importância dos Serviços de Distribuição para as economias em razão da demanda dispersa de seus produtos. As mesmas considerações podem ser aplicadas aos Serviços Produtivos, mas com uma ressalva: além da transferências desses serviços para o terciário estar em andamento, esse processo parece estar criando novas oportunidades que ampliam a sua dimensão e escopo. Adicionalmente, se somarmos valor adicionado e os elos (ILT) industriais e dos Serviços produtivos alcançamos cerca de $40 \%$ e $50 \%$ do total, respectivamente. Esses percentuais podem ser uma estimativa razoável dos impactos da indústria na economia.

As variações positivas nos Serviços Sociais expõem fatores relacionados ao processo de desenvolvimento econômico e social nos PED que podem ser sintetizado

\footnotetext{
${ }^{10}$ A qualidade irá depender de como o serviço é oferecido e os ganhos de eficiência nesse segmento estão
} relacionados com as TIC (FREUND e WEINHOLD, 2002). 
pelas mudanças de três segmentos (vide Tabela 5): os serviços de Correios e Telecomunicações (variação de $231 \%$ - os ventos da revolução nas tecnologias de comunicação, em particular, a móvel), Educação (48\%) e Saúde e Assistência Social (21\%). Esse desempenho levou os dois primeiros segmentos a níveis similares de elos ILT dos PD (cerca de $2,5 \%$ do total) e de valor adicionado (2\% e 4\%, respectivamente Tabela 3).

Considerando que estes serviços são antigas conquistas dos PD, as suas taxas de variações são comparativamente diminutas (Tabela 5). Em suma, o aumento da importância desses serviços nos últimos anos, está relacionado com a difusão das tecnologias (infraestrutura) de telecomunicações e com o envelhecimento da população e o concomitante crescimento dos gastos com previdência social em ambos os grupos de países.

\begin{tabular}{|c|c|c|c|c|c|c|c|c|c|c|c|c|c|c|c|c|c|c|c|c|c|}
\hline \multirow{2}{*}{ Países em Desenvolvimento } & \multicolumn{3}{|c|}{ Brasil } & \multicolumn{3}{|c|}{ China } & \multicolumn{3}{|c|}{ Índia } & \multicolumn{3}{|c|}{ Rússia } & \multicolumn{3}{|c|}{ México } & \multicolumn{3}{|c|}{ Coreia } & \multicolumn{3}{|c|}{ Média PeDs } \\
\hline & 1995 & 2010 & Var & 1995 & 2010 & Var & 1995 & 2010 & Var & 1995 & 2010 & Var & 1995 & 2010 & Var & 1995 & 2010 & Var & 1995 & 2010 & Var \\
\hline Correi & 1.43 & 3.54 & 147.6 & 0.53 & 2.63 & 398.1 & 0.00 & 1.64 & 164.5 & 0.00 & 1.87 & 186.7 & 1.12 & 3.03 & 169.7 & 1.53 & 2.54 & 65.7 & 0.77 & 2.54 & 230.6 \\
\hline Administração Pú & .71 & 4.25 & \begin{tabular}{|l|}
-25.7 \\
\end{tabular} & 4.49 & 3.75 & -16.3 & 0.00 & 0.00 & 0.0 & 6.80 & 5.87 & -13.8 & 2.25 & 6.06 & 169.7 & 3.57 & 3.99 & 11.6 & 3.80 & .99 & 4.8 \\
\hline Educação & 3.21 & 3.30 & 2.7 & 2.37 & 3.63 & 52.8 & 0.00 & 1.32 & 131.6 & 2.72 & 2.13 & -21.6 & 1.12 & 2.53 & 124.7 & 1.02 & 2.54 & 148.6 & 1.74 & 2.57 & 47.7 \\
\hline Saúde e A & 5.36 & 4.95 & -7.5 & 0.79 & 3.25 & 311.1 & 2.55 & 1.97 & -22.5 & 4.76 & 3.20 & -32.8 & 1.12 & 3.54 & 214.6 & 1.53 & 2.54 & 65.7 & 2.69 & 3.24 & 20.7 \\
\hline \multirow{2}{*}{ Países Desenvolvidos } & \multicolumn{3}{|c|}{ EUA } & \multicolumn{3}{|c|}{ Japão } & \multicolumn{3}{|c|}{ Alemanha } & \multicolumn{3}{|c|}{ França } & \multicolumn{3}{|c|}{ Itália } & \multicolumn{3}{|c|}{ Reino Unido } & \multicolumn{3}{|c|}{ Média PDs } \\
\hline & 1995 & \begin{tabular}{|l|}
2010 \\
\end{tabular} & Var & 1995 & 2010 & Var & 1995 & 2010 & Var & 1995 & 2010 & Var & 1995 & 2010 & Var & 1995 & 2010 & Var & 1995 & \begin{tabular}{|l|}
2010 \\
\end{tabular} & Var \\
\hline Correios e Telec & 2.83 & 3.39 & 19.8 & 1.97 & 2.40 & 21.5 & 1.41 & 2.17 & 53.7 & 2.13 & 2.30 & 7.9 & 1.72 & 2.59 & 50.3 & 4.09 & 3.95 & -3.5 & 2.36 & 2.80 & 18.6 \\
\hline Administração Pública e Defesa & 4.45 & 4.52 & 1.6 & 4.08 & 4.47 & 9.5 & 5.05 & 4.35 & -13.9 & 3.72 & 3.57 & -4.1 & 3.69 & 3.67 & -0.6 & 4.68 & 4.86 & 4.0 & 4.28 & 4.24 & -0.9 \\
\hline Educação & 2.02 & 2.54 & 25.8 & 2.82 & 2.08 & -26.3 & 2.02 & 2.39 & 18.4 & 3.19 & 2.55 & -20.1 & 0.99 & 0.86 & -12.3 & 3.22 & 4.26 & 32.3 & 2.38 & 2.45 & 3.0 \\
\hline Saúde e Assistência Social & 3.64 & 3.95 & 8.7 & 3.80 & 3.99 & 5.0 & 3.64 & 3.91 & \begin{tabular}{ll|}
7.6 \\
\end{tabular} & 4.26 & $\begin{array}{l}4.08 \\
\end{array}$ & -4.1 & 3.45 & 3.46 & 0.2 & 4.68 & 5.47 & 16.9 & 3.91 & \begin{tabular}{|l|l|}
4.14 \\
\end{tabular} & 6.0 \\
\hline
\end{tabular}

Tabela 5 - Participação dos Serviços Sociais no Índice de Ligação para Trás - ILT (\%) Obs.: Var: variação no período; PED: países em desenvolvimento; PD: países desenvolvidos.

Fonte: World Input-Output Database (WIOD). Elaboração própria.

Por fim, os assim como nas proporções de valor adicionado, os Serviços Pessoais são díspares nos dois blocos de países. A capacidade de indução desses serviços nos PED (5,7\% em 2010) é significativamente menor do que nos PD (10,6\%). Essa característica expõe (e reforça) a melhor qualidade de vida nos $\mathrm{PD}$, pois envolvem maior diversificação (número de elos).

Em termos de Índice de Ligação para Frente (ILF), os Serviços de Distribuição e Produtivos reforçam a sua participação (acima de 20\%), embora a Indústria se mantenha, em geral, como a mais relevante - média para os PED de 33\% em 1995 e $36 \%$ em 2010 e para os PD a média de 32,5\% em 1995 e 29,6\% em 2010. Em síntese, também neste indicador os bens industriais mantêm elos de oferta relativamente mais significativos que as demais atividades. Além disso, há diferenças significativas da intensidade entre os países, como nos casos da Coreia (ILF de 40,2\% em 2010) e Reino Unido (16,1\%), ressalte-se quase metade dos Serviços Produtivos (30,4\%).

Entre os grupos dos setores do terciário, os Serviços Produtivos são os mais relevantes, ou seja, são os mais importantes na cadeia produtiva de outros setores. Também nesses serviços há diferenças entre os países: por exemplo, no México representaram 35\% da participação em 2010, na China, 14,9\%, e nos EU, 17,1\%. No entanto, somadas as participações ILF da Indústria e dos Serviços Produtivos, exceto para o Reino Unido, o resultado também é superior a $50 \%$.

\section{Considerações finais}

As atividades de serviços apresentam elevada heterogeneidade, dada pelas suas características tecnológicas e estruturais. Este estudo contribui para este aspecto da 
literatura analisando a composição das atividades dos serviços em diferentes países e ressaltando as disparidades entre os países desenvolvidos e em desenvolvimento.

Nas últimas décadas, as inovações em processo, diferenciação de produtos e criação de novos modelos de negócios, permitiram que as atividades de serviços aumentassem a sua parcela no valor gerado nas economias. As etapas pré-produção e pósprodução estão sendo transferidas, construídas e/ou reforçadas dentro de certos segmentos de serviços, que os capacitam como intensivos em conhecimentos e fortemente vinculados com a indústria. Assim, os serviços tornam-se fundamentais para intensificar a capacidade de inovação, produção, circulação, distribuição e regulação das atividades produtivas. Nesse sentido, este estudo assume o papel dos serviços como complementar as atividades manufatureiras e refuta a visão de rivalidade.

Os resultados relativos ao valor adicionado confirmam a queda da participação da indústria de transformação nas economias analisadas. Todavia, essa redução parece vir acompanhada, principalmente, do aumento dos serviços produtivos. Esse fenômeno, que ocorre antes e com maior intensidade nos PD, reforça as teses de especialização e terceirização dessas atividades nesses países de forma mais acentuada do que nos PED e de concentração em atividades com maior potencial para adicionar valor. Em adição, apesar do elevado crescimento da indústria de transformação nos PED, ela é ainda cerca de metade dos PD, ou seja, esses últimos ainda mantêm o domínio em setores secundários e avançam na direção as atividades de serviços complementares.

Os resultados alcançados evidenciam também o aumento dos Serviços Sociais (em geral, públicos) em grande parte dos países, fator que demonstra a importância de componentes políticos e sociais no processo de desenvolvimento. Os Serviços de Pessoais variaram de acordo com o país apresentando menores magnitudes nos PED. Esse diferencial pode decorrer de distintos aspectos relatados na literatura: pelos níveis de renda per capita entre os dois blocos e/ou pelo aumento da qualidade dos serviços oferecidos nos PD, em geral, fruto da diferenciação.

Em relação aos vínculos entre as atividades econômicas, a indústria de transformação mantém-se como o setor mais relevante, principalmente em termos de capacidade de indução para trás dada a sua característica especial demandante de bens e serviços.

A interação entre a indústria e setor de serviços parece representar uma relação sistêmica para o crescimento de ambos. Dois grupos de serviços são fundamentais nesse processo: serviços de distribuição - com alta relevância nos PED e nos PD e pouca variação no período e; serviços produtivos - com efeitos heterogêneos entre PED e PD. Neste último segmento, houve uma relativa convergência que reforça a terceirização e especialização tardia nos países do primeiro bloco. Por outro lado, a comparação entre o ILT e ILF demonstra que a capacidade da indústria de transformação de impulsionar o setor de serviços é mais elevada do que o contrário, e em proporção expressiva em todos os países. 


\section{Referências Bibliográficas}

ARBACHE, J. Produtividade no Setor de Serviços. Produtividade no Brasil: Desempenho e Determinantes, BNDES, v. 2, RJ. 2015.

BAUMOL, W. J. 'Macroeconomics of Unbalanced Growth: the Anatomy of Urban Crisis'. In: American Economic Review, Vol. 57, pp. 415 - 426. 1967.

BRESSER-PEREIRA, L. C.; MARCONI, N. Existe Doença Holandesa no Brasil? In: Bresser-Pereira, L. C. (org.), Doença holandesa e indústria (coletânea). Editora FGV. Rio de Janeiro. 2010.

CANO, W. A desindustrialização no Brasil. Texto para discussão ${ }^{\circ}$ 200, IE/UNICAMP. Janeiro. Campinas. 2012.

CASTELLACCI, F. Technological paradigms, regimes and trajectories: Manufacturing and service industries in a new taxonomy of sectoral patterns of innovation. Research Policy, v. 37, n. 6, p. 978-994, 2008.

CLARK, C. (1940, revised and reprinted in 1951) The Conditions of Economic rogress. London: MacMillan \& Co. Ltd. 1951

FEIJÓ, C. A. E CARVALHO, P. G. M. Desindustrialização e os Dilemas do Crescimento Econômico Recente. IEDI, mimeo. São Paulo: IEDI. 2007.

FISHER, A.G.B. The Clash of Progress and Security. London: MacMillan \& Co. Ltd. 1935.

GALLOUJ, Faïz; SAVONA, Maria. Innovation in services: a review of the debate and a research agenda. Journal of Evolutionary Economics, v. 19, n. 2, p. 149-172, 2009.

GOYAL, S. Connections: An Introduction to the Economics of Networks, Princeton University Press, Princeton and Oxford. 2007.

GOMES, Rogério. Complexos Econômicos no Brasil: Um Algoritmo Computacional. Dissertação de mestrado. Instituto de Matemática, Estatística e Ciência da Computação, UNICAMP. Campinas, 1992.

GREENHALGH, C; GREGORY, M. Structural change and the emergence of the new service economy. Oxford Bulletin of Economics and Statistics, v. 63, n. s1, p. 629-646, 2001.

GUILHOTO, J. GEOFFREY JD H e EDUARDO B. M. "Índices De Ligações E Setores Chave Na Economia Brasileira: 1959-1980 (Linkages and Key-Sectors in the Brazilian Economy: 1959-1980)." Pesquisa e Planejamento Econômico 24, no. 2 (1994): 287-314. 1994.

GUILHOTO, J. J. M. e SESSO FILHO, U. A. Estimação da Matriz Insumo-Produto a Partir de Dados Preliminares das Contas Nacionais. Economia Aplicada. Vol. 9, $\mathrm{n}^{\circ}$, abrjun. 2005.

HAUSMANN, R., HIDAlGO, C. A., BUSTOS, S., COSCIA, M., SIMOES, A., e YILDIRIM, M. A. The atlas of economic complexity: Mapping paths to prosperity. Mit Press. 2014.

HIRSCHMAN, A. The Strategy of Economic Development. Yale University Press. 1958. HOWELLS, Jeremy. Where to from here for services innovation. In: A paper presented at the Knowledge Intensive Services Activities (KISA) Conference, Sydney. 2006. 
KALDOR, N. Problems of Industrialization in Underdeveloped Countries. Ithaca: Cornell University Press. 1967.

KON, A. Sobre a Economia Política do desenvolvimento e a Contribuição dos Serviços. Revista de Economia Política, v. 27, p. 130-146, 2007.

KON, A. Atividades de serviços como indutoras do desenvolvimento. Revista da Sociedade Brasileira de Economia Política, v. 34, p. 57-77, 2013.

KONGSAMUT, P., REBELO, S. E; XIE, D. Beyond balanced growth. Review of Economic Studies 68: 869-882. 2001.

KUZNETS, S. Quantitative aspects of the economic growth of nations: II. Industrial distribution of national product and labour force. Economic Development and Cultural Change 5 (supplement): 3-111. 1957.

KUZNETS, S. Modern Economic Growth: Rate, Structure, and Spread. New Haven, CT: Yale University Press. 1966.

MIOZZO, M; SOETE, L. Internationalization of services: a technological perspective. Technological Forecasting and Social Change, v. 67, n. 2, p. 159-185, 2001.

NASSIF, A. Há Evidência de Desindustrialização no Brasil? Revista de Economia Política. v. 28, nº 1, jan/mar. p. 72-96. 2008.

RASMUSSEN, P. N. Studies in inter-sectoraI reIations. Amsterdarn, North-Holland, 1956.

OCDE (2013) Interconnected Economies: Benefiting from global value chains. New York and Geneva., United Nations. 2013.

PALMA, J. G. Quatro fontes de industrialização e um novo conceito de doença holandesa. Texto apresentado na conferência sobre industrialização e desindustrialização, FIESP/IEDI. 2005.

PARK, S. H., \& CHAN, K. S. A cross-country input-output analysis of intersectoral relationships between manufacturing and services and their employment implications. World Development, 17(2), 199-212, 1989.

PAVITT, K. Sectoral Patterns of Technical Change: towards a taxonomy and a theory. Research Policy, vol 13, 1984.

PREBISCH, R. O desenvolvimento da América Latina e seus principais problemas. Revista Brasileira de Economia. Ano 3, n 3, Setembro. Rio de Janeiro: Fundação Getúlio Vargas. 1949.

ROWTHORN, R.; RAMASWAMY, R. Growth, Trade and Deindustrialization. International Monetary Fund Staff Papers, Vol. 46, N.1. 1999

THIRLWALL, A. P. A Natureza do Crescimento Econômico: um referencial alternativo para compreender o desempenho das nações. Editora do IPEA. Brasília. 2005.

SAVIOTTI, P.P. Chapter 2 - Knowledge Networks: Structure and Dynamics. In A. Pyka, A. Scharnhorst (eds.), Innovation Networks, Understanding Complex Systems, DOI 10.1007/978-3-540-92267-4 2, C Springer-Verlag Berlin Heidelberg. 2009.

SCHETTKAT, R.; YOCARINI, L. The shift to services employment: A review of the literature. Structural Change and Economic Dynamics 17.2 (2006): 127-147. 2006. 
SINGELMANN, J. The sectoral transformation of the labor force in seven industrialized countries, 1920-1970. American Journal of Sociology, p. 1224-1234, 1978.

SINGH, A. Manufacturing and de-industrialization. In: Eatwell, J.; Milgate, M. 1987.

TREGENNA, F. Characterising deindustrialisation: An analysis of changes in manufacturing employment and output internationally. Cambridge Journal of Economics, 33, 433-466. 2008.

WIOD (2014), World Input-Output Database, disponível em: http://www.wiod.org/new_site/home.htm. 2014. 